\title{
Simulation and Analysis of the Deflagration in the Starting Process of Oxygen/Oil Gas Jet Heater
}

\author{
Qi Bin ${ }^{1,2, *}$, Yang Chi ${ }^{2}$, Lou Wenzhong ${ }^{1}$, Zou Yang-hui ${ }^{2}$, Tian Ning ${ }^{2}$ \\ ${ }^{1}$ Beijing Institute of Technology, Beijing 100081, China \\ ${ }^{2}$ Beijing Institute of Space Long March Vehicle, Beijing 100076, China
}

\begin{abstract}
In order to study the pressure peak caused by deflagration in starting process of gas jet heater, a simulation method was carried out. The deflagration simulation was divided into cold-test and hot-test processes. The mass conservation equation, energy conservation equation and oxygen/oil combustion reaction equation were used to analyze the pressure of combustion chamber in both cold-test and hot-test. The analysis results suit well with the prototype test which shows the applicability of the method. Based on this method, peak pressure of the deflagration under a given condition was calculated. The peak pressure calculated (13.5MPa) exceeded the design pressure (5Mpa), which led to the damage of the gas jet heater.
\end{abstract}

\section{Introduction}

High temperature gas jet heater is used for generating high temperature and high pressure gas source as the core equipment of hypersonic flight vehicle thermal protection assessment tests [1][2]. Total temperature inside the main heater is as high as $3600 \mathrm{~K}$, total pressure is as high as several $\mathrm{MPa}$, and therefore the working condition is very poor. Starting process is one of the riskiest links in the whole test process during in the working process of main heater.

Abnormal starting of heater often leads to deflagration or explosion, heater damage or security problem. Ignition delay is one of the most important factors of deflagration. Pressure impact process produced by deflagration is at millisecond magnitude, actual pressure peak value can not be easily captured by pressure sensor. And it is difficult to reconstruct. Cheng Mousen, etc. introduced status quo and existing problems of liquid hydrogen oxygen engine pre-cooling and starting process numerical simulation study [3]. Jin Zhongwei, etc. utilized FIRE software developed by AVL Company for numerical simulation on combustion process in car heater combustion chamber [4]. Related articles about gas heater deflagration are rare.

In the paper, deflagration during starting process of oxygen/oil gas jet heater is studied. Mass conservation equation, combustion chemical reaction, energy conservation equation, pressure balance equation, are adopted to establish dynamic mathematical model of heater starting process. Cold-test and hot-test starting process, deflagration produced by ignition delay of the main heater are simulated and analyzed. They are compared with experimental data for verifying applicability of the method and model. Instant pressure peak value of deflagration is obtained. The above method can be used for analyzing starting state and deflagration of similar main heater or liquid rocket engine.

\section{Working Principle and Deflagration Process}

The gas jet heater mainly includes sprayer, combustion chamber, nozzle and ignition device. Combustion chamber volume is $0.002 \mathrm{~m}^{3}$. Nozzle throat diameter is $0.025 \mathrm{~m}$. Principle of 'feeding oxygen followed by oil' is adopted for gas jet heater startup sequence. Oxygen is fed into combustion chamber through sprayer. Meanwhile, ignition device is ignited. Flame is fed into combustion chamber through the throat. Then, kerosene oil is sprayed into combustion chamber through sprayer. Oxygen and kerosene oil droplet are rapidly combusted. Hightemperature and high pressure gas source is produced in combustion chamber. Gas source passes through nozzle, and then forms high temperature supersonic gas jet for thermal protection test. Principle and the gas jet heater are shown in Figure 1 and figure 2.

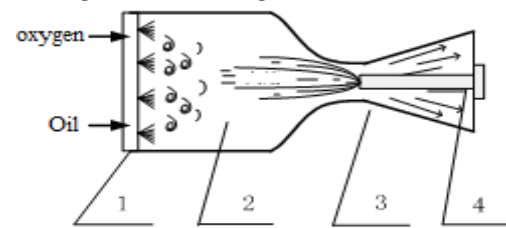

1-- sprayer; 2-- combustion chamber; 3--nozzle; 4-ignition device

Figure 1. The working sketch of gas jet heater



Figure 2. The test rig of gas jet heater

If a large number of mixture of oxygen and kerosene oil is accumulated in combustion chamber, deflagration can be produced at the moment of ignition. Gas pressure will be increased suddenly to a high value and lead to combustion chamber or sprayer damage [5]. Deflagration is usually caused by ignition delay. 


\section{Mathematical Models}

\subsection{Basic assumptions}

When mathematical model of high temperature and high pressure gas source generation process is established, the following assumptions are made:

1) Fuel staying and atomization time after being fed into the combustion chamber is neglected in the process of combustion, namely the fuel is rapidly combusted;

2) Fuel gas belongs to ideal gas;

3) All parameters in combustion chamber are uniformly distributed;

4) Heat flow rate transmitted by combustion products to chamber wall is ignored;

\subsection{Basic equations}

The following mathematical model is established according to the above assumptions [6]:

Mass conservation equation of combustion air source in main heater:

$$
\frac{d m_{c}}{d t}=\dot{m}_{\text {in }}-\dot{m}_{\text {out }}
$$

Accumulation rate of gas mass in main heater is equivalent to the difference between fuel mass inflow volume $\dot{m}_{\text {in }}$ and outflow volume $\dot{m}_{\text {out }}$.

Energy conservation equation of combustion gas source in main heater:

$$
\frac{d H_{c}}{d t}=\dot{H}_{\text {in }}-\dot{H}_{\text {out }}
$$

Namely, the accumulation rate of enthalpy $H_{c}$ of combustion gas source in the main heater is equivalent to the difference between enthalpy inflow volume $\dot{H}_{\text {in }}$ and outflow volume $\dot{H}_{\text {out }}$, and unit is J.

The above-mentioned mass conservation equation and energy conservation equation are fragmented:

1) Gas mass $m_{c}$ in the combustion chamber can be determined by state equation:

$$
m_{c}=\frac{P_{c} \cdot V_{c} \cdot M_{c}}{R_{0} \cdot T_{c}}
$$

Wherein, $P_{c}$ refers to pressure in the combustion chamber with unit of $\mathrm{Pa} ; T_{c}$ refers to temperature in combustion chamber with unit of $\mathrm{K} ; V_{c}$ refers to combustion chamber volume with unit of $\mathrm{m} 3 ; R_{0}$ refers to gas universal constant with unit of $\mathrm{J} / \mathrm{kmol}, \mathrm{K} ; M_{c}$ refers to gas molecular weight in combustion chamber, which is related to pressure, temperature and gas composition in combustion chamber.

2) Gas mass inflow volume $\dot{m}_{i n}$ refers to the sum of oxygen provided for the main heater and kerosene oil mass flow rate:

$$
\dot{m}_{i n}=\dot{m}_{\mathrm{O}_{2}}+\dot{m}_{\text {oil }}
$$

Oxygen flow rate $\dot{m}_{O 2}$ and kerosene oil flow rate $\dot{m}_{\text {Oil }}$ depend on the difference between oxygen oil inlet pressure and pressure of main heater combustion chamber as well as flow resistance characteristics of sprayer. Flow value measured in the test can be selected with unit of $\mathrm{kg} / \mathrm{s}$.

3) Gas mass outflow volume $\dot{m}_{\text {out }}$ can be determined by nozzle size and the combustion chamber state.

$$
\dot{m}_{\text {out }}=P_{c} \cdot A_{t} \cdot \sqrt{\frac{M_{c}}{R_{0} \cdot T_{c}}} \cdot \sqrt{\gamma\left(\frac{2}{\gamma+1}\right)^{\frac{\gamma+1}{\gamma-1}}}
$$

Wherein, $A_{t}$ refers to main heater nozzle throat cross section area with unit of $\mathrm{m} 2, \gamma$ refers to specific heat ratio of gas, which is related to pressure, temperature and gas composition in the combustion chamber.

4) Enthalpy value in energy conservation equation is the product of corresponding mass and specific enthalpy, wherein the specific enthalpy numerical value is related to temperature and composition.

\subsection{Gas calculation method}

Main chemical reactions in kerosene oil $\mathrm{C}_{\mathrm{n}} \mathrm{H}_{2 \mathrm{n}}$ and oxygen $\mathrm{O}_{2}$ combustion are shown as follows [7]:

$$
\begin{aligned}
& \mathrm{C}_{\mathrm{n}} \mathrm{H}_{2 \mathrm{n}}+\mathrm{O}_{2} \rightarrow \mathrm{CO}_{2}+\mathrm{H}_{2} \mathrm{O} \\
& \mathrm{CO}_{2}+\mathrm{H}_{2} \Leftrightarrow \mathrm{CO}+\mathrm{H}_{2} \mathrm{O} \\
& \mathrm{CO}_{2} \Leftrightarrow \mathrm{CO}+0.5 \mathrm{O}_{2} \\
& \mathrm{H}_{2} \mathrm{O} \Leftrightarrow \mathrm{H}_{2}+0.5 \mathrm{O}_{2} \\
& \mathrm{H}_{2} \mathrm{O} \Leftrightarrow \mathrm{HO}+0.5 \mathrm{H}_{2} \\
& \mathrm{H}_{2} \Leftrightarrow 2 \mathrm{H} \\
& \mathrm{O}_{2} \Leftrightarrow 2 \mathrm{O}
\end{aligned}
$$

Partial pressure of all components in combustion product: $p_{\mathrm{CO}_{2}}, p_{\mathrm{CO}}, p_{\mathrm{H}_{2} \mathrm{O}}, p_{\mathrm{H}_{2}}, p_{\mathrm{OH}}, p_{\mathrm{O}_{2}}, p_{\mathrm{H}}$ and $p_{\mathrm{O}}$, and partial pressure balance equation between combustion chamber pressure and various gases is shown as follows:

$$
p_{\kappa}=p_{\mathrm{CO}_{2}}+p_{\mathrm{CO}}+p_{\mathrm{H}_{2} \mathrm{O}}+p_{\mathrm{H}_{2}}+p_{\mathrm{OH}}+p_{\mathrm{O}_{2}}+p_{\mathrm{H}}+p_{\mathrm{O}}
$$

Partial pressures of various gases are shown as follows according to balance constant equation:

$$
\begin{gathered}
p_{C O}=\frac{K_{P 1}}{\sqrt{p_{O_{2}}}} \cdot p_{C_{2}} \\
p_{H_{2}}=\frac{K_{P 2}}{\sqrt{p_{O_{2}}}} \cdot p_{H_{2} \mathrm{O}} \\
p_{O H}=\frac{K_{P 3}}{\sqrt{p_{H_{2}}}} \cdot p_{H_{2} O} \\
p_{H}=\sqrt{K_{P 5}} \cdot \sqrt{p_{H_{2}}} \\
p_{O}=\sqrt{K_{P 6}} \cdot \sqrt{p_{O_{2}}}
\end{gathered}
$$

Material balance equation: contents of all elements in fuel before combustion are equivalent to the content of all elements in the combustion product. $C_{T}, H_{T}$ and $O_{T}$ masses of carbon, hydrogen and oxygen elements in unit mass fuel.

$$
\frac{2 \cdot\left(p_{\mathrm{H}_{2} \mathrm{O}}+p_{\mathrm{H}_{2}}\right)+p_{\mathrm{OH}}+p_{\mathrm{H}}}{p_{\mathrm{CO}_{2}}+p_{\mathrm{CO}}}=12 \cdot \frac{H_{T}}{C_{T}}=A
$$




$$
\frac{2 \cdot\left(p_{\mathrm{CO}_{2}}+p_{\mathrm{O}_{2}}\right)+p_{\mathrm{CO}}+p_{\mathrm{H}_{2} \mathrm{O}}+p_{\mathrm{OH}}+p_{\mathrm{O}}}{p_{\mathrm{CO}_{2}}+p_{\mathrm{CO}}}=\frac{3}{4} \cdot \frac{O_{T}}{C_{T}}=B
$$

All physical property parameters of mixed gas is are calculated according to formula (21) and gas composition obtained by calculation[8]' including molar mass $M_{c}$, molar specific heat at constant pressure $C_{P}$ with unit of $\mathrm{J} / \mathrm{mol}, \mathrm{K}$, specific heat ratio $\gamma$ and specific enthalpy $h_{c}$ with unit of $\mathrm{J} / \mathrm{kg}$.

$$
\chi=\frac{\sum_{i} p_{i} \cdot \chi_{i}}{p_{\kappa}}
$$

Wherein, $\chi$ is a physical parameter of gas; $\chi_{i}$ is a corresponding physical parameter of one gas component; $p_{i}$ refers to partial pressure of one component with unit of $\mathrm{Pa} ; p_{\kappa}$ refers to total pressure for gas with unit of $\mathrm{Pa}$.

\subsection{Boundary conditions}

Oxygen and kerosene oil flow rates are adopted as the boundary conditions of calculation. They are selected according to experimental measurement.

\subsection{Simplified treatment of kerosene oil spraying}

When oxygen and kerosene oil are sprayed into combustion chamber and not ignited, except the oxygen builds pressure in the combustion chamber, after kerosene oil is atomized and impacted by sprayer, very small oil mist particles can be formed by breaking, which participate pressure building in combustion chamber. In the paper, complex liquid atomization process is not deeply studied. Such an assumption is adopted for approximate solution to kerosene oil atomization and pressure building problem, namely kerosene oil atomized by sprayer is also regarded as a gas for meeting ideal gas state equation. Therefore, oil mist and oxygen can be considered as mixed gas. kerosene oil is $\mathrm{C}_{15} \mathrm{H}_{32}$, molar mass is $M_{\text {oil }}=212(\mathrm{~kg} / \mathrm{kmol})$.

\section{Calculation Results}

\subsection{Cold - test}

Cold-test is implemented according to hot-test parameters in order to Verified the method. Oxygen and kerosene oil are sprayed into the combustion chamber. Ignition device does not ignite. Oxygen and kerosene oil flow curves are got as calculation input condition under cold-test state.

According to mass conservation equation, Pressurebuilding curves can be obtained as shown in figure 4 . The simulation pressure fits well with the test pressure. Two small fluctuation peaks are caused by oxygen flow supply. Simulation fluctuation is smaller than measured data. The results show that the treatment method of kerosene oil atomization contribution to chamber pressure is rational, which can be used for combustion chamber pressure simulation before deflagration and calculation of oxygen kerosene oil mixed gas mass.

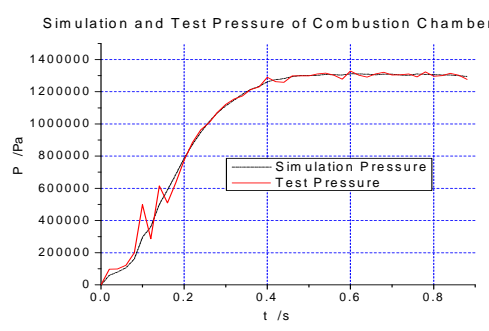

Figure 4. Simulation and test pressures of combustion chamber

\subsection{Hot-test}

Hot-test state is simulated and tested in order to verify combustion and pressure calculation methods. A group of flow curves of oxygen and kerosene oil are selected as calculation input conditions as shown in figure 5.

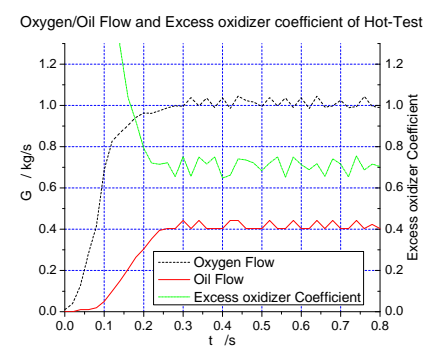

Figure 5. Flow and excess oxidizer coefficient of hot-test

According to mass conservation equation and energy conservation equation, The hot-test results are shown in figure 8 . The results show that the calculation pressure is basically consistent with measurement value. It is verified that mathematical model and calculation method are feasible. Measured pressure shows twice abnormal fluctuations in the initial boosting stage. Pressure building process of combustion chamber is a process of sharp change of combustion state, which may have certain instability or pulse. Sampling frequency of data acquisition equipment is just $50 \mathrm{HZ}$, sampling time is 20 $\mathrm{ms}$, pressure impact peak value is not captured.

Figure 6 also shows that the chamber temperature rising process should be prominently earlier than chamber pressure. Combustion temperature is mainly related to the mixing ratio of oxygen and kerosene oil, which basically can not be affected by pressure and total fuel flow rate. The combustion chamber pressure rising process belongs to a dynamic balance process that should meet fuel inflow mass and throat outflow gas mass relationship, which is slower than temperature rising rate.

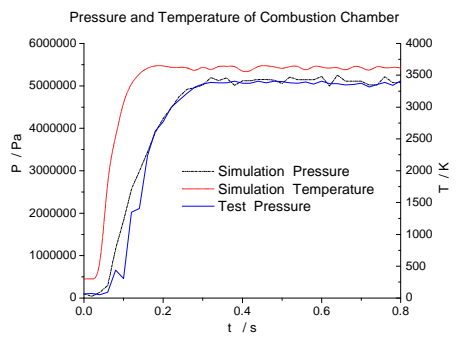

Figure 6. Pressure and temperature of combustion gas 


\subsection{Deflagration state}

Oxygen and kerosene oil flow curves before 'deflagration' are selected as calculation boundary conditions, shown in figure 7. After "deflagration", combustion chamber has been obviously deformed, the sprayer is also damaged, and the flow data is meaningless.

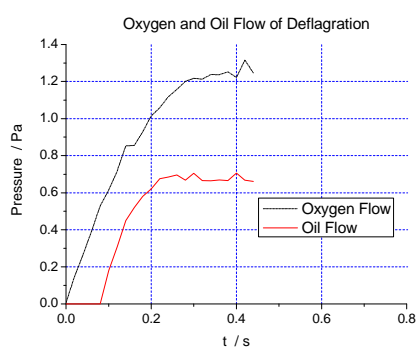

Figure 7. The oxygen and oil flow before deflagration

Chamber pressure curve is calculated according to the mass conservation equation. Mixture of oxygen and kerosene oil is ignited and combusted at 0.42s time point. The total fule is the sum of the mass at last time point adding spraying mass at the current time point. Combustion chamber pressure is calculated according to hot-test calculation method. The calculation results are shown in figure 8. Before ignition, the calculated chamber pressure fits well with the test measurement. $11.5 \mathrm{Mpa}$ is detected by pressure sensor at the moment of deflagration, and it is damaged since the value is higher than the measuring range. Calculated pressure value is 7.25 MPa, which is higher than 5.0 $\mathrm{MPa}$, but lower than the measurement pressure.

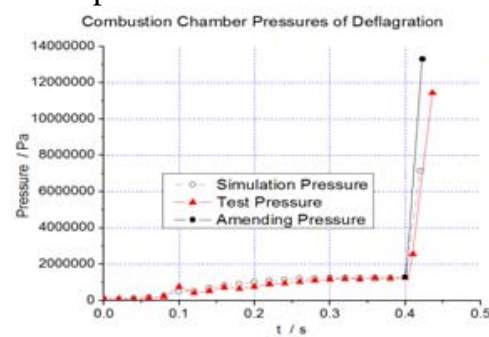

Figure 8. Combustion chamber pressure of deflagration

Kerosene oil droplets can be attached and stored on the chamber wall actually, deflagration pressure should be higher than simulation result. $0.4 \mathrm{~s}$ Cold-test is repeated, Kerosene oil mass accumulated in the chamber is $0.048 \mathrm{~kg}$. Considering Kerosene oil accumulated on the inner wall of combustion chamber, the calculation results show that combustion chamber pressure reaches 13.4MPa instantly during deflagration, which is far higher than the design pressure of $5 \mathrm{MPa}$, which is enough to damage the heater completely.

\section{Summary}

In the paper, in order to obtain pressure peak value produced by deflagration during starting process of gas jet heater, combustion chamber pressure building processes under cold-test and hot-test states are tested and calculated. Applicability of the calculation method is verified, and the following conclusions are obtained.
(1) Mass conservation equation is mainly adopted for the dynamic pressure model under cold -test state, kerosene oil droplet can be considered as ideal gas, wich contributes the pressure-building process;

(2) Mass conservation equation, energy conservation equation, combustion chemical reaction and pressure balance equation are mainly adopted for the dynamic pressure model under hot-test state. The calculation results fit well with test measurement results, which can be used for modeling and simulation of starting process of similar main heaters and liquid rocket engine;

(3) Deflagration can be divided into two states, namely cold-test and hot-test. If only mixture gas of oxygen and kerosene oil is considered, the calculation pressure peak is smaller than test pressure. Kerosene oil accumulated on the wall of chamber should be considered.

\section{References}

[1] Laub, B., Balboni, J. and Goldstein, H., "Ground Test Facilities for TPS Development”. NASA T M2002-211400, NASA Ames Research Center, Moffett Field, California, May 2002.

[2] Qi Bin, Lou Wenzhong, Tian Ning, etc. Analysis on high temperature supersonic gas jet field thermal environment for thermal protection test. Aerospace Material Technology, 2014, 44 (5):30-35.

[3] Cheng Mou-sen, Liu Kun, Zhang Yu-lin. Review on the models and numerical methods for simulation of precooling and starting process of LOX/LH_2 rocket engine. Journal of Propulsion Technology. 2002,23(3):177-181.

[4] Jin Zhongwei, Chen Kangmin, Ye Zhou, etc. Numerical simulation of combustion in automobile heater. 2006,28(6):566-570;

[5] Liu Guoqiu. Liquid rocket engine principle. Beijing: China Astronautic Publishing House,2009.

[6] Cao Taiyue. Rocket engine dynamics. Changsha: National University of Defense Technology Publishing House, 2004.

[7] Edited by Ehsan Balun. Shiweiliuke, Translated by Bao Yuxiang, etc. Design theory foundation of liquid rocket engine. Shanghai: Shanghai Publishing House, 1963.

[8] Edited by Ehsan Balun, Translated by Cheng Nailiang, etc. Pure substance thermochemical data handbook. Science Press, 2003 